\section{Hear from leaders in implant dentistry}

Over recent years, healthcare innovations have changed the way in which dentistry is performed. Education and training has become crucial to cope with new technologies, materials and treatment methods. Therefore, BioHorizons continuously provides education tailored to the needs of dental professionals and announces two upcoming courses featuring leaders in the implant field.

On Saturday, 13th October 2018, in Dublin, Professor Tiziano Testori, Head of Implant Dentistry and Oral Rehabilitation, University of Milan, will discuss 'Immediate Loading: State of the Art', focussing on achieving an immediate loading protocol by reducing the number of surgical interventions, as well as shortening the time between surgery and prosthetic delivery, all without sacrificing implant success rates.

'Communication-based Implant Dentistry with Dr Lincoln Harris' is scheduled for Thursday, 18th October 2018, in London. Dr Harris is a clinician in a private practice and will discuss how to communicate effectively with patients suitable for implant treatment. He will challenge delegates' thinking on how effective they really are at communicating with their patients and cover deeper and more effective patient communication, how communication can reduce failure rates, effective planning for complex and simple cases and dealing with complications.

For further information visit www.theimplanthub.com/ education, email educationuk@biohorizons.com or call 01344752560 .

\section{Disinfectant meets British Standard}

Constantly striving to help dental practices achieve infection control compliance, Nuview recently tested its Continu Dental Unit Waterline Disinfectant to assess biofilm removal and prevention in line with the new BS EN ISO 16954 standard. The Continu solution is thought to be the first weekly treatment of its kind to be tested to this standard.

During a three-week test period, the treatment resulted in no viable planktonic bacteria and no viable biofilm bacteria being recovered so the Continu Disinfectant for Dental Unit Waterlines was shown to disrupt mixed species biofilms for all three weeks. Furthermore the tests showed that Continu inhibited biofilm reformation between treatments.

The results demonstrate that Continu offers an excellent solution to biofilm removal in a single weekly treatment, saving practices time and money, whilst ensuring compliance to the HTM 01-05 requirement for periodic disinfection of Dental Unit Waterlines.

For more information please call Nuview on 01453872266 , emailinfo@nuview-ltd.com,or visit www.nuview.co.uk

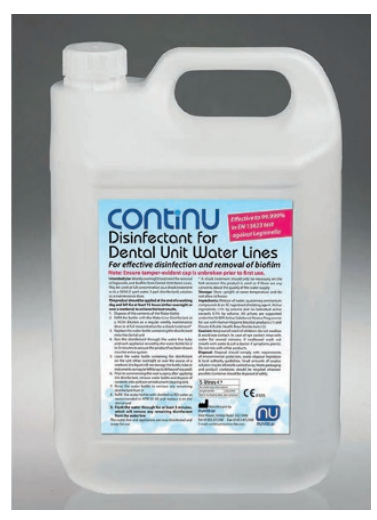

\section{Fifty-two years on}

Since launching its first Little Sister in 1966, Eschmann has been at the forefront of innovation in decontamination equipment design, not only in terms of performance but functionality and reliability too.

Today, Eschmann provides a number of products, including the Little Sister SES 2010 11-litre non-vacuum autoclave and Little Sister SES3000B 17-litre vacuum autoclave, as well as a range of accessories.

All equipment is available alongside the unrivalled Care\&Cover Lifetime Protection, which includes two scheduled service visits each year, annual validation, unlimited breakdown call-outs, verifiable CPD training, and more.

For more information on the highly effective and affordable range of decontamination equipment and products from EschmannDirect, please visit www.eschmann.co.uk or call 01903753322.

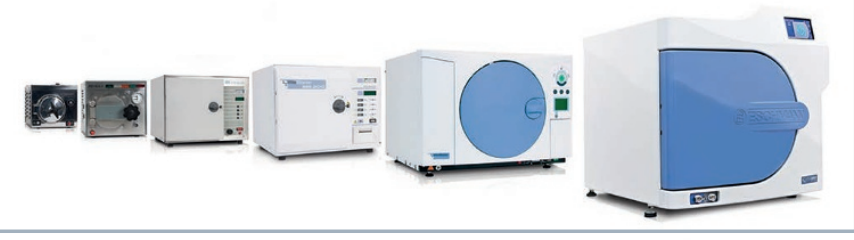

Keeping their guard up

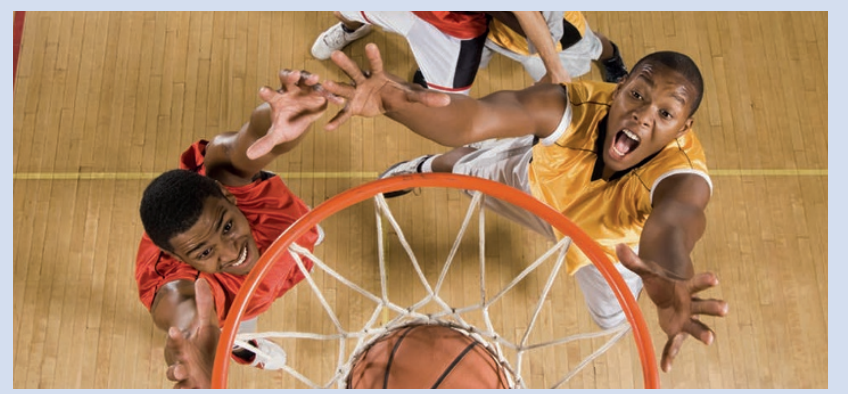

Dental trauma can occur in basketball just as often as in contact sports like rugby and boxing.

Make sure your patients are protected whenever they head to the courts with the Saber Protect mouth guard from CosTech Dental Laboratory.

Completely bespoke to the patient's oral cavity, Saber Protect is the proven way to help prevent and lessen the harmful effects of dental trauma for patients who play basketball and other limited contact sports.

Specifically designed to guard the mouth, lips, gums and head, Saber Protect mouth guards are moulded to reflect the sport that the patient plays, offering tailored protection no matter whether they are a beginner or a professional.

Each mouth guard shields against different impact levels, providing shock absorbency in the places that most need protection. As such, you can guard your patients from harmful effects such as tooth avulsion and other potential injuries by providing them with a mouth guard they can really rely on.

For more information about CosTech Dental Laboratory, visit www.costech.co.uk or call 01474320076. 